\title{
Identification of Designer Drugs using Gas Chromatography High-Resolution Mass Spectrometry and A Soft-Ionization Source
}

\author{
Lopez-Avila $\mathrm{V}^{*}$ \\ Agilent Technologies, USA
}

*Corresponding author: Lopez-Avila V, Agilent Technologies, Santa Clara, CA 95051, USA, Fax: (408) 553 3677, Tel: (408) 553-2709, E-mail: viorica_lopez-avila@agilent.com

Citation: Lopez-Avila V (2013) Identification of Designer Drugs using Gas Chromatography High-Resolution Mass Spectrometry and a Soft-Ionization Source. J Forensic Sci Criminol 1(3): 301. doi: 10.15744/23489804.1.301

Received Date: September 27, 2013 Accepted Date: December 11, 2013 Published Date: December 16, 2013

\begin{abstract}
A small set of amphetamines has been analyzed by gas chromatography (GC) high-resolution time-of-flight mass spectrometry (TOFMS) using a microplasma photoionization (MPPI) soft-ionization source. This plasma-based, wavelength selectable ionization source enables ionization of the test compounds and their corresponding derivatives at $\sim 8-12 \mathrm{eV}$ that is a softer alternative to electron ionization at $70 \mathrm{eV}$. Three plasma gases were used in this study: Xe plasma that emits photons at resonance lines of $9.57 \mathrm{eV}$ and $8.44 \mathrm{eV}$; Kr plasma at $10.63 \mathrm{eV}$ and $10.02 \mathrm{eV}$, and Ar plasma at $11.82 \mathrm{eV}$ and $11.61 \mathrm{eV}$. Derivatization of the test compounds with trifluoroacetic anhydride and $\alpha$-methoxy- $\alpha$-(trifluoromethyl)-phenylacetyl pyrazole was evaluated because the MPPI mass spectra of the underivatized amphetamines yield primarily iminium ions, which make the identification of the test compounds by GC-TOFMS inconclusive. The MPPI mass spectra of the TFA-derivatized amphetamines yield abundant molecular ions, when using $\mathrm{Xe}$ as plasma gas, and enough fragment ions with the Ar plasma that can help in formula generation. The structure elucidation of two "known unknowns" designer drugs using this "tunable" soft-ionization source and a high-resolution TOF mass spectrometer is presented in this study.
\end{abstract}

\section{Introduction}

Gas chromatography-mass spectrometry (GC-MS) with electron ionization (EI) or chemical ionization (in positive or negative mode) plays an important role in the forensic analysis of designer drugs. Whereas targeted GC-MS with EI works well whenever reference analytical standards are available for testing or the EI mass spectra of targeted compounds are included in databases, the detection and characterization of unknown substances is difficult because reference standards for newly released designer drugs are commonly not available and the mass spectra of such designer drugs often lack the molecular ion from which a molecular formula could be derived. Alternative approaches to the conventional EI for GC-MS include softer ionization techniques (i.e., EI with 15 $\mathrm{eV}$ electrons [1], chemical ionization [2], photoionization [3]) but with the exception of the chemical ionization source, the low-energy EI and the photoionization sources are not commercially available on the GC low-resolution MS systems. Liquid-chromatography (LC) with electrospray ionization (ESI) MS has become a frequently employed tool because ESI is a soft ionization technique, which typically yields protonated molecular ions, and no derivatization is required to separate compounds by liquid chromatography. A review of the analytical techniques used in forensic science can be found elsewhere [4].
GC-MS with conventional EI using $70 \mathrm{eV}$ electrons is often preferred over LC-MS, despite the fact that for certain applications derivatization is needed to reduce polarity and increase analyte volatility, because of its higher sensitivity, far better chromatographic resolution of the GC column as compared to the LC column and the low susceptibility to matrix effects in the case of biological samples [5]. Among the LCMS approaches, LC-atmospheric pressure chemical ionization (APCI) was found to work very well for a series of illicit designer drugs including MDA (3,4-methylenedioxy-amphetamine), MDMA (3,4-methylenedioxymethamphetamine), and MDEA (3,4-methylenedioxyethylamphetamine) because of the soft ionization achieved with the APCI source, thus yielding very abundant molecular ions [6]. The use of LC-high resolution MS (i.e., TOFMS and Orbitrap systems) in clinical toxicology, which has been discussed in detail by Wu et al. [7], offered unique opportunities in clinical analysis of untargeted drugs because ESI is a soft ionization yielding intact molecular ions, and high resolution facilitated the generation of molecular formulae of such ions. A HR-MS system [i.e., quadrupole(Q) TOFMS], interfaced to a GC was not commercially available until early 2012, and a HR TOFMS is not yet available commercially. 
Differentiation of positional isomers is valuable in forensic analysis as legal controls are often placed on one of the positional isomers [8] and a combination of chemical derivatization GC-low resolution MS and LC-MS/MS were used to differentiate between the positional isomers of three fluoroamphetamines and three fluoromethamphetamines [8]. In another recent publication, Sekula and Zuba [9] report that GC-MS with $70 \mathrm{eV}$ EI and LC-QTOFMS with ESI are complementary analytical tools because the mechanisms of fragmentation under different ionization conditions lead to different mass spectra for 2-(4-iodo-2,5-dimethoxyphenyl)$\mathrm{N}$-[(2,3-methylenedioxyphenyl)-methyl]-ethanamine, psychoactive drug discovered in 2012.

This study was undertaken to explore the use of chemical derivatization and soft ionization GC-TOFMS in the identification of a few known designer drugs, and thus to establish whether such methodology could be applied to the identification of similar designer drugs. Soft ionization is achieved here with vacuum ultraviolet (VUV) light produced by a split-ring resonator microplasma device. This windowless device uses rare gases at 3-5 $\mathrm{mL} / \mathrm{min}$ and delivers approximately $1 \mathrm{~W}$ of RF power at $2.5 \mathrm{GHz}$. The three plasma gases used in this study were pure $\mathrm{Xe}, 10 \% \mathrm{Kr}$ in helium, and pure Ar. A schematic diagram of the prototype MPPI soft-ionization source has been presented previously [10]. Although this study was performed with a research TOFMS, a commercial QTOFMS with an EI source is now commercially available from Agilent Technologies.

\section{Experimental: (Materials and Methods)}

\section{Chemicals and reagents}

Test compounds (Figure 1) were purchased from Cerilliant (Round Rock, TX). Stock solutions of the individual amphetamines were in methanol at concentrations of $1 \mathrm{mg} /$ $\mathrm{mL}$ and were stored at $4{ }^{\circ} \mathrm{C}$. Ten to $100 \mu \mathrm{L}$ working standard solutions of the individual compounds or the composite solutions were evaporated to dryness under a gentle stream of nitrogen and the residue was used for derivatization. Trifluoroacetic anhydride ReagentPlus (> 99\%), was purchased from Sigma-Aldrich (St. Louis, MO). The derivatization reagent, (+)- $\alpha$-methoxy- $\alpha$-(trifluoromethyl)-phenylacetyl pyrazole (MTPA-pyrazole) was purchased from Wako Chemicals USA, Inc. (Richmond, VA) and was stored at $-20^{\circ} \mathrm{C}$ prior to use. Spectroscopic-grade ethyl acetate and methylene chloride were purchased from J.T. Baker (Phillipsburg, NJ) and EMD (Gibbstown, NJ), respectively. Research Plus grade $\mathrm{Xe}$ and ultra-high purity $10 \% \mathrm{Kr}$ in helium were purchased from Scott Specialty Gases (Plumsteadville, PA) and ultrahigh purity Ar was purchased from Airgas USA, LLC (Long Beach, CA).

\section{Derivatization with trifluoroacetic anhydride}

A $100 \mu \mathrm{L}$ aliquot of trifluoroacetic (TFA) anhydride/ethyl acetate $(5: 1, \mathrm{v} / \mathrm{v})$ was added to each vial containing either residue from either a single test compound or a composite solution, and the vial was capped, its contents were mixed with a vortex mixer, and then heated at $80^{\circ} \mathrm{C}$ for $10 \mathrm{~min}$ on a hotplate stirrer (Optichem digital hotplate stirrer, Chemglass, Life Sciences, Vineland, NJ ). After cooling to room temperature, the excess TFA/ethyl acetate was removed by evaporation to dryness under a gentle stream of nitrogen and redisolved in 50 $\mu \mathrm{L}$ of ethyl acetate.

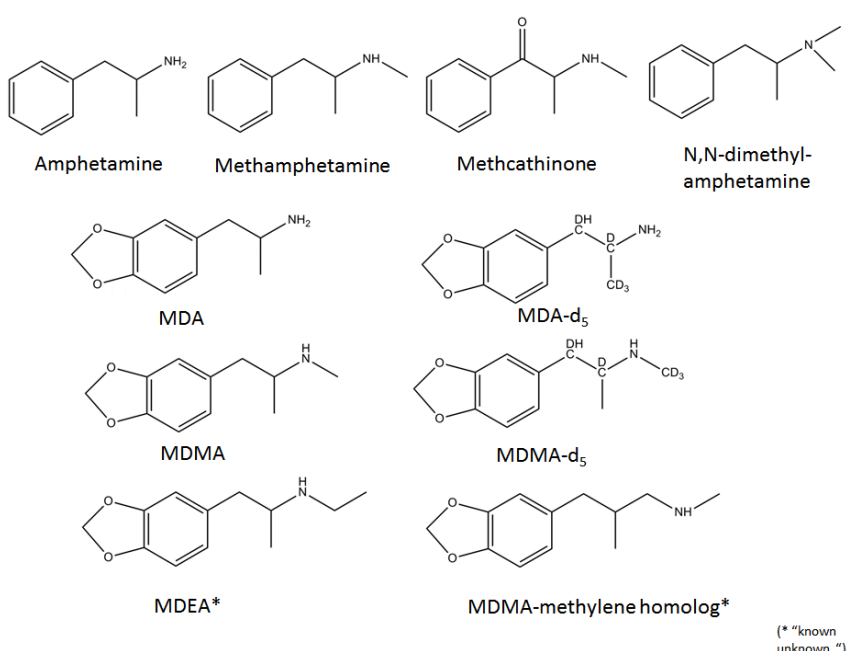

Figure 1: Chemical structures of the test compounds

\section{Derivatization with MTPA pyrazole}

A $100 \mu \mathrm{L}$ aliquot of the stock solution of MTPA-pyrazole [11] in ethyl acetate at $12.3 \mathrm{mg} / \mathrm{mL}$ was added to the vial containing the test compound(s) that needed to be derivatized and the vial was capped, its contents were mixed, and then heated at $80{ }^{\circ} \mathrm{C}$ for $10 \mathrm{~min}$ on a hotplate stirrer. After cooling to room temperature, the excess reagent was removed by evaporation to dryness under a gentle stream of nitrogen and the residue was redisolved in $100 \mu \mathrm{L}$ of ethyl acetate.

\section{GC chromatographic conditions}

The chromatographic separation was performed using an Agilent (Santa Clara, CA) 7890A GC modified to accommodate a low-thermal module (LTM) column. Standards were introduced into the GC via a $30 \mathrm{~m}$ x $0.25 \mathrm{~mm}$ id x $0.25 \mu \mathrm{m}$ film thickness LTM HP-5MS capillary column also from Agilent Technologies. The column temperature was programmed from $50^{\circ} \mathrm{C}$ to $245^{\circ} \mathrm{C}$ at $35^{\circ} \mathrm{C}$ and then to a final temperature of $300{ }^{\circ} \mathrm{C}$ at $15^{\circ} \mathrm{C} / \mathrm{min}$, where it was held for $3 \mathrm{~min}$. Helium was used as carrier gas at a flowrate of $1.2 \mathrm{~mL} / \mathrm{min}$. The injector temperature was $250{ }^{\circ} \mathrm{C}$, the source temperature was $175^{\circ} \mathrm{C}$ and the GC-MS transfer line temperature was $300{ }^{\circ} \mathrm{C}$. The injector fitted with a double tapered liner was set in splitless mode for $2 \mathrm{~min}$ after the injection (purge flow was $50 \mathrm{~mL} /$ $\min )$.

\section{Mass Spectrometry}

The exact mass measurements were collected with a research TOF mass spectrometer, equipped with the above mentioned microplasma photoionization (MPPI) source, and operated in the positive ion mode. The TOF mass spectrometer was a modified Agilent 6200 Accurate -Mass TOF LC/MS system with a flight path of $2 \mathrm{~m}$ that was upgraded with a $4-\mathrm{GHz}$ data 
acquisition system. Spectral data were acquired at a rate of 5 scans/sec and the mass range for data acquisition was 42 to 600 u. The mass axis was calibrated daily with perfluorotributylamine, which was delivered to the ionization source via the GC transfer line. The mass resolution of the TOF mass spectrometer was approximately 10,000 (full width at half maximum, FWHM) at $m / z 271.9867$.

In the MPPI source the gaseous analyte flows through a channel in the plenum and it is exposed to the VUV light through an orifice. The microplasma is offset from the sample ionization channel, allowing metastable excited atoms and ground state neutral gas to be dispersed before entering the ionization region. Electrostatic deflectors, situated between the output of the plasma device and the orifice in the sample channel, prevent plasma ions and electrons from entering the ionization zone and interacting with the analyte. The sample ions are extracted and formed into a beam using a custom ion source based on the design of the Agilent Technologies EI source.

Data processing was performed using the MassHunter Qualitative Analysis software (Agilent Technologies, version B.05.00) and possible ion formulae were obtained using the Qual Formula Calculator algorithm incorporated in the software. Formula generation allowed the use of up to $30 \mathrm{C}, 60$ $\mathrm{H}, 5 \mathrm{O}, 3 \mathrm{~N}$, and $6 \mathrm{~F}$ atoms and the "odd electron" (i.e., $\mathrm{M}^{+\bullet}$ ) feature in generating the formulae of the molecular ions.

\section{Results and Discussion}

In the process of identifying a compound using GC-MS, one would usually start with the analysis of the underivatized compound using the conventional EI with $70 \mathrm{eV}$ electrons. Following data acquisition, the EI mass spectrum will be searched against a library of mass spectra and the compound retention time will be checked against those of reference standards analyzed under identical GC conditions as the analyte that is to be identified. Unfortunately, when dealing with designer drugs some of the mass spectra might not be in the library and/or they may yield only a fragment ion at a low $m / z$ ratio from which an identification can be very difficult, often impossible. This is the case of designer drugs related to amphetamine and cathinone, in which different functional groups (i.e., alkyl, alkoxy, F) have been introduced either on the phenyl- or the 3,4-methylenedioxyphenyl-ring [12], or on the amine moiety. Regardless of the chemical functionality added on the aromatic ring, the only abundant ions in their EI spectra are the iminium ions $\mathrm{C}_{2} \mathrm{H}_{6} \mathrm{~N}, \mathrm{C}_{3} \mathrm{H}_{8} \mathrm{~N}$, and $\mathrm{C}_{4} \mathrm{H}_{10} \mathrm{~N}$ (Table 1). It was hypothesized in this study that by using a softer ionization it might be possible to reduce fragmentation and enhance the relative intensity of the molecular ions for such type of designer drugs. However, even when choosing a photon energy (i.e. Xe at $8.44 \mathrm{eV}$ ) that is only slightly higher than the vertical ionization energy of some of the test compounds (i.e., fluoromethcathinone at $8.33 \mathrm{eV}$ ), the iminium ions at $\mathrm{m} / z 44.0495, \mathrm{~m} / z 58.0651$ and $\mathrm{m} / z 72.0808$ were still the most abundant ions in the mass spectra of the amphetamines and cathinones listed in Table 1. The exceptions were of the chlorinated and brominated amphetamines, etilefrine, and fenfluramine, which have not been tested yet. In the case of the 3,4-methylenedioxyamphetamines (i.e., MDA and MDMA), the molecular ions were in the range of $20-40 \%$ relative intensity for Xe-MPPI and $<2 \%$ relative intensity for $\mathrm{Kr}$ and Ar-MPPI, and the overall sensitivity of the underivatized amphetamines was poor with Xe plasma. Therefore, derivatization of the amine moiety was considered in order to improve chromatography, instrument sensitivity, and obtain additional information either from the molecular ion of the derivatized compound or from its fragment ions, which would help in the identification process by MS. Two derivatization procedures: trifluoroacetyl derivatization with TFAA and derivatization with chiral MTPA pyrazole were evaluated side by side. The latter was reported by Matsushita et al. [11] and was evaluated here to establish whether the optical isomers of amphetamines can be separated chromatographically, and to find out whether the soft ionization source would yield abundant molecular ions.

\begin{tabular}{|c|c|c|}
\hline $\begin{array}{l}\text { Amphetamines with } \\
\text { BP @ } m / z \mathbf{4 4}\left(\mathbf{C}_{2} \mathbf{H}_{6} \mathbf{N}\right)\end{array}$ & $\begin{array}{l}\text { Amphetamines with } \\
\mathbf{B P} @ m / z \mathbf{5 8}\left(\mathbf{C}_{3} \mathbf{H}_{8} \mathbf{N}\right)\end{array}$ & $\begin{array}{l}\text { Amphetamines with } \\
\text { BP @ } m / z 72\left(\mathbf{C}_{4} \mathbf{H}_{10} \mathbf{N}\right)\end{array}$ \\
\hline Amphetamine & Methamphetamine & $\begin{array}{l}\text { N,N-dimethylamphet- } \\
\text { amine }\end{array}$ \\
\hline Methyl-amphetamine & $\begin{array}{l}\text { Methyl-methamphet- } \\
\text { amine }\end{array}$ & Methadone \\
\hline $\begin{array}{l}\text { Methoxy-ampheta- } \\
\text { mine }\end{array}$ & $\begin{array}{l}\text { Methoxy-metham- } \\
\text { phetamine }\end{array}$ & Fenfluramine \\
\hline $\begin{array}{l}\text { F-, Cl-, Br-ampheta- } \\
\text { mine }\end{array}$ & $\begin{array}{l}\text { F-, Cl-, Br-metham- } \\
\text { phetamine }\end{array}$ & N-ethylamphetamine \\
\hline MDA & MDMA & MDEA \\
\hline Heptaminol & p-Hydroxyephedrine & Mephentermine \\
\hline Norpseudoephedrine & Ephedrine & Methylephedrine \\
\hline Tuaminoheptane & Methylone & Ethylone \\
\hline \multirow[t]{7}{*}{ Cathinone } & Methcathinone & Butylone \\
\hline & Methyl-methcathinone & Metamphepramone \\
\hline & $\begin{array}{l}\text { F-, Cl-, Br-methcathi- } \\
\text { none }\end{array}$ & Buphedrone \\
\hline & $\begin{array}{l}\text { Methoxy-methcathi- } \\
\text { none }\end{array}$ & \\
\hline & Phentermine & \\
\hline & Etilefrine & \\
\hline & Cl-phentermine & \\
\hline
\end{tabular}

${ }^{*}$ there could be other amphetamines with base peaks (BP) at $m / z 44,58$, and 72

Table 1: List of amphetamines whose EI mass spectra yield base peaks at $m / z$ 44,58 , and $72^{*}$

\section{GC-high resolution TOFMS of MDA and MDMA and their TFA derivatives using soft-ionization}

The Xe-MPPI spectra of several TFA-derivatives of model substances are shown in Figure 2. The Kr- and Ar-MPPI mass spectra of the TFA derivatives of MDA, MDA-D5, MDMA and MDMA-D5 are shown in Figures 3 and 4. In contrast to EI with $70 \mathrm{eV}$ and even $20 \mathrm{eV}$ electrons, where the molecular ions of the TFA-derivatives are barely detectable $[13,14]$, the soft ionization with Xe plasma yielded molecular ions with 100\% relative intensity and minimal fragmentation, while Kr-MPPI and Ar-MPPI (Figures 3 and 4) gave lower relative intensities 

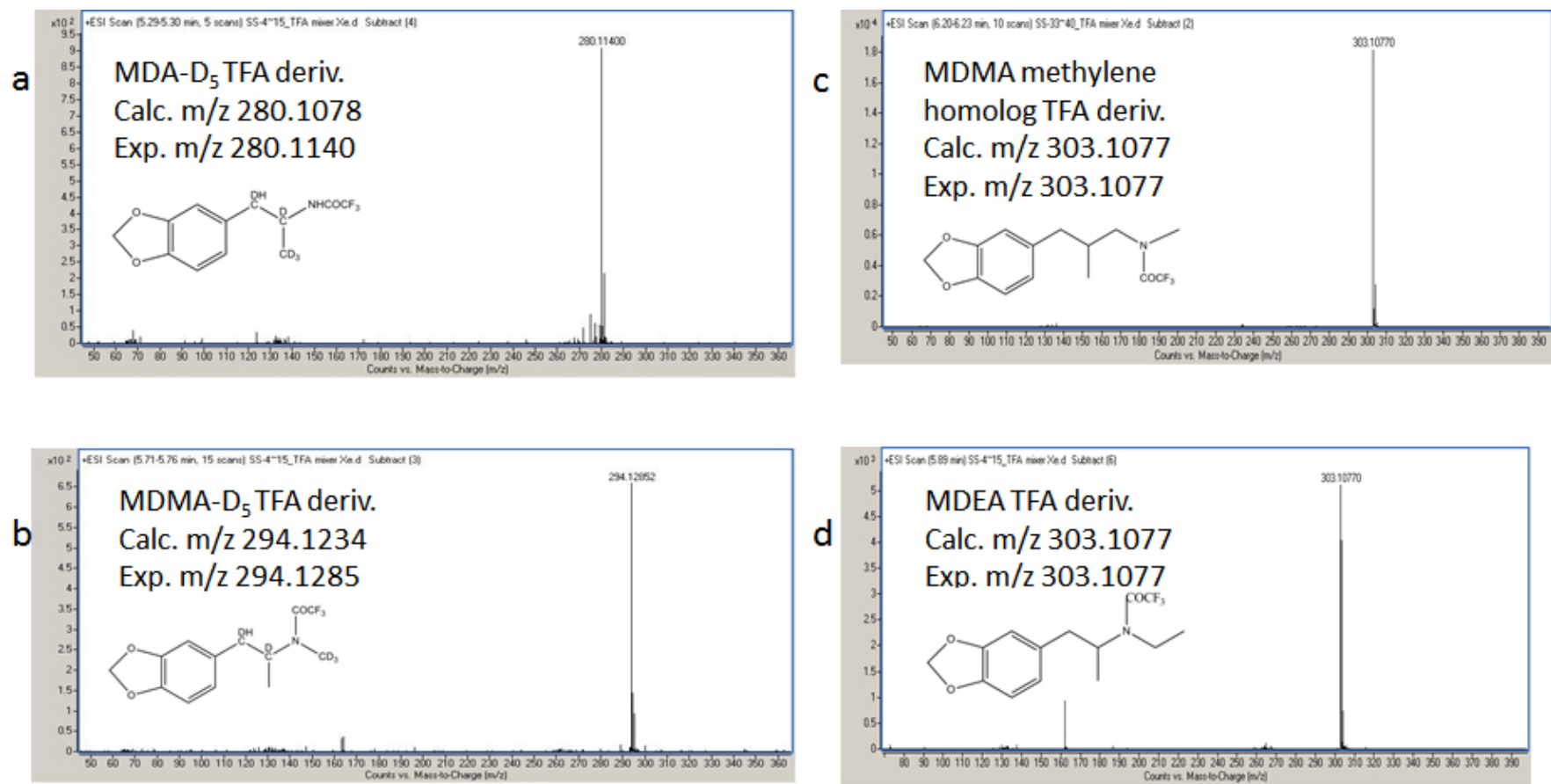

Figure 2: Xe-MPPI spectra of the TFA-derivatives of (a) MDA- $\mathrm{D}_{5}$, (b) MDMA- $\mathrm{D}_{5}$, (c) MDMA methylene homolog, and (d) MDEA. The spectra were obtained by GC-TOFMS with the MPPI source using Xe as plasma gas.
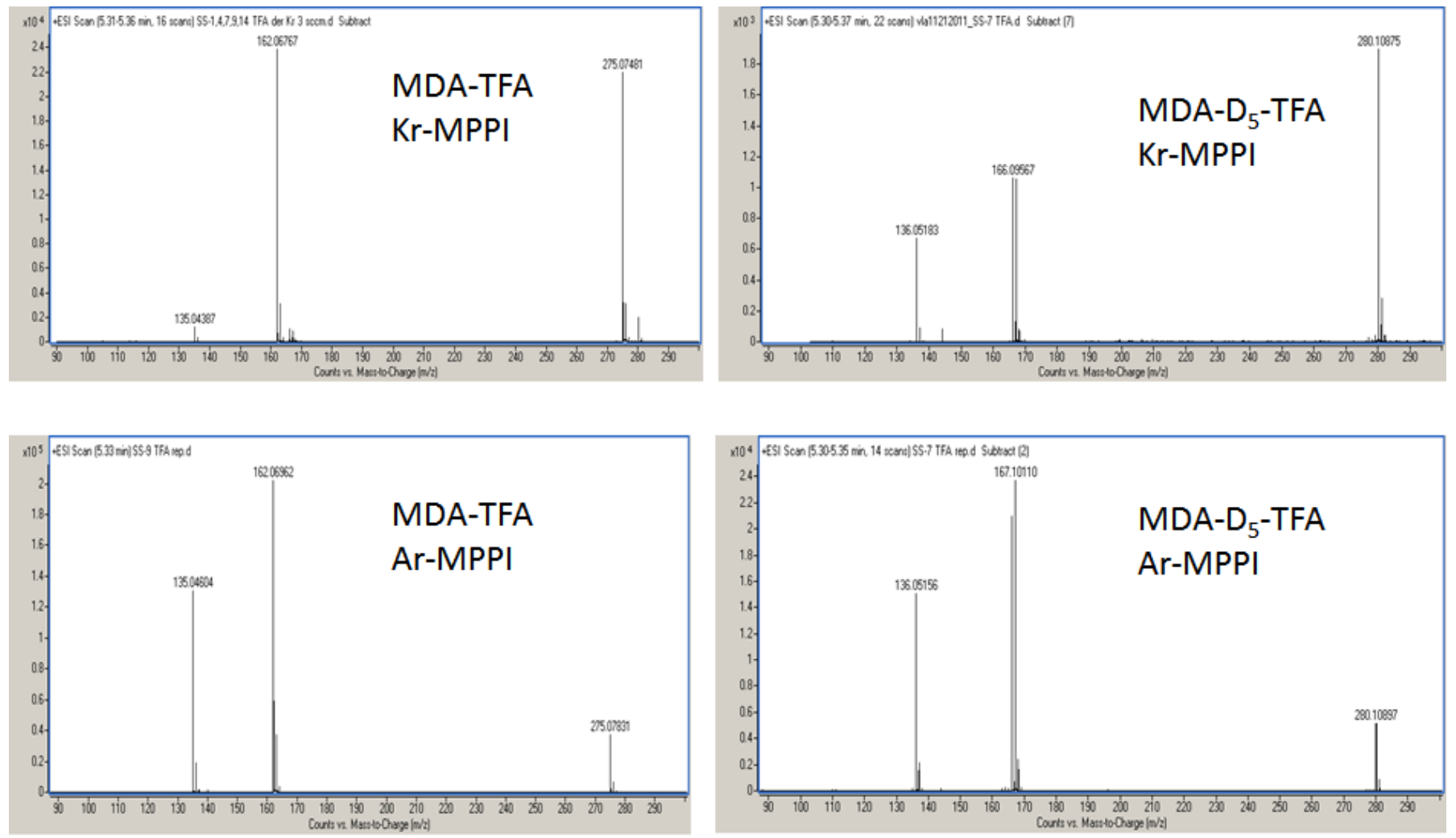

Figure 3: Kr-MPPI and Ar-MPPI spectra of the TFA derivatives of MDA and MDA- $\mathrm{D}_{5}$. The spectra were obtained by GC-TOFMS with the MPPI source using $\mathrm{Kr}$ or Ar as plasma gases.

for the molecular ions, especially in the case of Ar plasma, and more fragmentation, as expected.

The advantages of being able to vary the ionization energy are multifold. For example, in the case of the TFA derivatives of 3,4-methylenedioxyamphetamines like MDA- $\mathrm{D}_{5}$, MDMA-D , and the two "known unknowns" MDEA and MDMA methylene homolog, the molecular ions were the only ions in the
Xe-MPPI spectra (Figure 2) and, as expected, their relative intensities decreased when switching to Kr-MPPI and ArMPPI (Figures 3 and 4). These spectra show that the degree of fragmentation can be controlled with the plasma gas, because different plasma gases generate distinct VUV resonance lines (i.e., $\mathrm{Xe}$ at $8.44 \mathrm{eV}, \mathrm{Kr}$ at 10.64/10.03 eV and $\mathrm{Ar}$ at 11.83/11.62 $\mathrm{eV})$. This has also been observed for stimulants like cocaine, codeine, nicotine, methadone, fencamfamine [10], 25 cathi- 

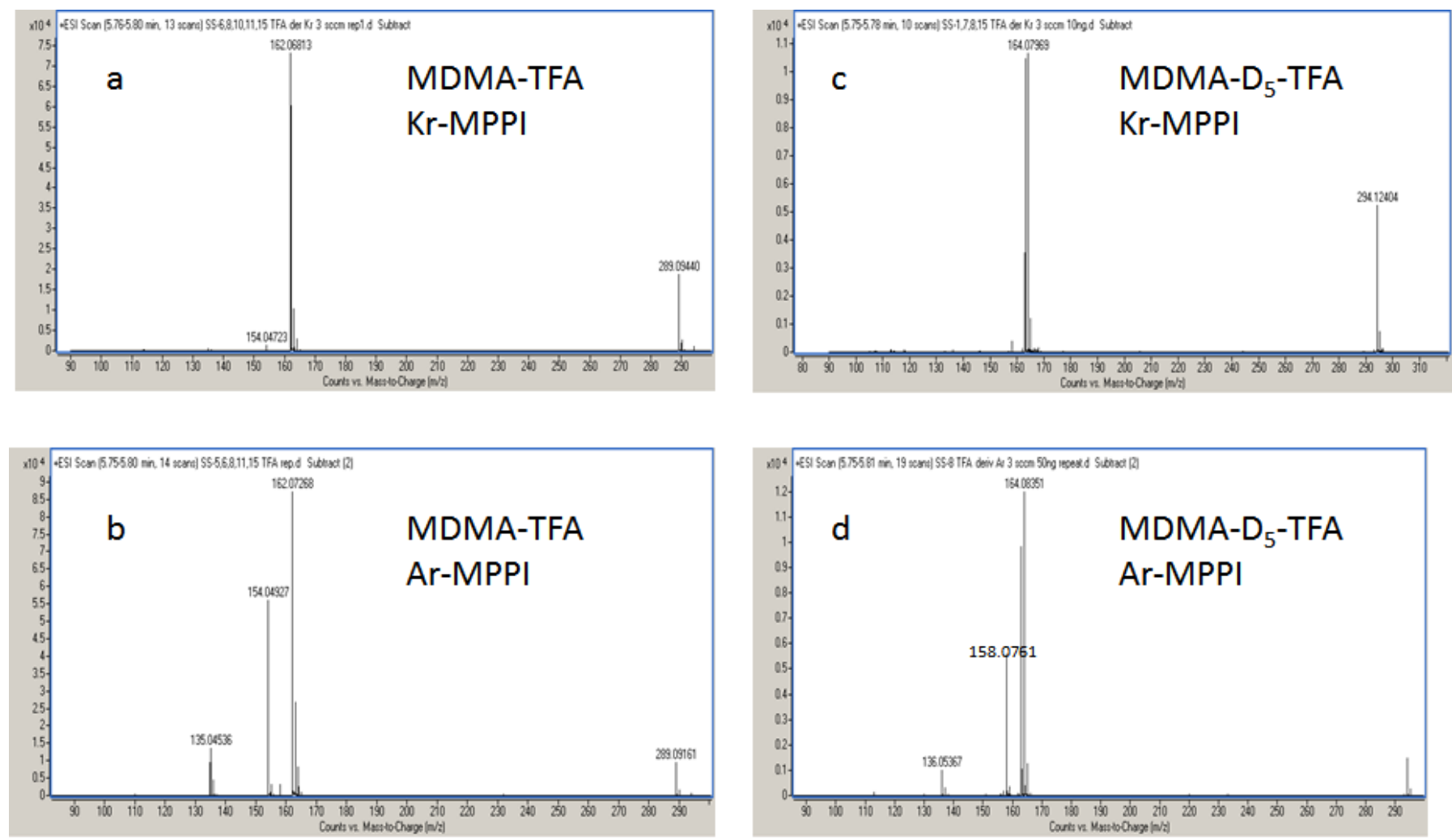

Figure 4: Kr-MPPI and Ar-MPPI spectra of the TFA derivatives of MDMA-TFA and MDMA-D ${ }_{5}$-TFA. The spectra were obtained by GC-TOFMS with the MPPI source using $\mathrm{Kr}$ or $\mathrm{Ar}$ as plasma gases.

nones also derivatized with TFAA [15] and polycyclic aromatic sulfur heterocycles [16].

The distinct fragment ions for the TFA derivatives of MDA and MDMA (Figures 3 and 4) are the ions at exp. $m / z$ 162.0677162.0727 corresponding to the 3,4-methylenedioxy-phenylpropene radical cation $\left(\mathrm{C}_{10} \mathrm{H}_{10} \mathrm{O}_{2}\right.$, calc. $m / z$ 162.0691). This formula was confirmed using the TFA derivatives of the deuterated analogs of MDA and MDMA, which resulted in a shift of the $m / z$ ratio for 3,4-methylenedioxy-phenyl-propene radical cation of $5 \mathrm{u}$ for MDA-D ${ }_{5}$ and $2 \mathrm{u}$ for MDMA-D ${ }_{5}$. In the case of MDMA-D, the 2-u shift was expected as the three D atoms are in the $\mathrm{N}$-methyl group $\left(\mathrm{N}-\mathrm{CD}_{3}\right)$ that is eliminated in the form of a neutral imine species. The formation of the 3,4-methylenedioxy-phenyl-propene radical cation was suggested to occur via a $\mathrm{H}$-rearrangement involving migration of a $\mathrm{H}$ atom from the alkyl group to the carbonyl oxygen followed by the loss of the imine species [13,14]. The Kr-MPPI spectra of the MDA- $\mathrm{D}_{5}$ and MDMA- $\mathrm{D}_{5}$ indicate that either the $\mathrm{H}$ or the $\mathrm{D}$ atom attached to the $\beta$-carbon are likely to transfer because the relative intensities of the resulting deuterated 3,4-methylenedioxy-phenyl-propene radical cations at $\mathrm{m} / \mathrm{z}$ $166.0957 / 167.1012$ and $m / z$ 163.0740/164.0797 (for Kr plasma) and $m / z 166.0950 / 167.1011$ and $m / z 163.0775 / 164.0835$ (for Ar plasma), respectively, are very similar (Figures 3 and 4).

In addition, a fragment ion corresponding to the 3,4-methylenedioxy-benzyl ion at $m / z 135.0441$, produced via $\alpha$-cleavage of the amide bond of the corresponding molecular ion, tends to be more abundant for MDA rather than MDMA in ArMPPI. The deuterated MDA and MDMA exhibit ions at $\mathrm{m} / z$
136.0516-136.0537 corresponding to the replacement of one $\mathrm{H}$ atom with a $\mathrm{D}$ atom in the 3,4-methylenedioxy-benzyl ion. The iminium ions at $m / z 154.0493$ and $m / z 158.0761$ were only observed in the MPPI spectra of MDMA and MDMA-D, respectively. This was not unexpected, as the 4-u shift is due to the presence of three $\mathrm{D}$ atoms in the $\mathrm{N}$-methyl group and one $\mathrm{D}$ atom that is being transferred from the $\beta$ carbon.

\section{Identification of "known unknowns" designer drugs}

"Known unknowns" have been defined as compounds that are actually known in the chemical literature, reference databases, or an internet resource but they are unknown to the investigator [17]. The discussion below addresses how one could apply the knowledge gathered from the high-resolution MS with soft ionization of a certain designer drugs (i.e., MDA and MDMA), in the identification of "known unknowns" drugs (Figure 5). To start, obtain the Xe spectrum of the underivatized compound shown Figure 6a, which yields an abundant ion at $m / z 72.0817$ with $100 \%$ relative intensity with formula $\mathrm{C}_{4} \mathrm{H}_{10} \mathrm{~N}$ according to the MassHunter Qual algorithm and an ion at $m / z 207.1279$ (relative intensity $<10 \%$ ), which might be the molecular ion. This information is very valuable, despite the fact that the most abundant ion is at low mass, because it provides the first clue that the "known unknown" contains an amine functional group. This amine could be a primary, secondary or tertiary amine but derivatization will only take place if the amine is primary or secondary. Proceed with derivatization and record the Xe-, Kr-, and Ar-MPPI spectra. Establish the monoisotopic mass of the molecular ion for the derivatized compound. Upon 


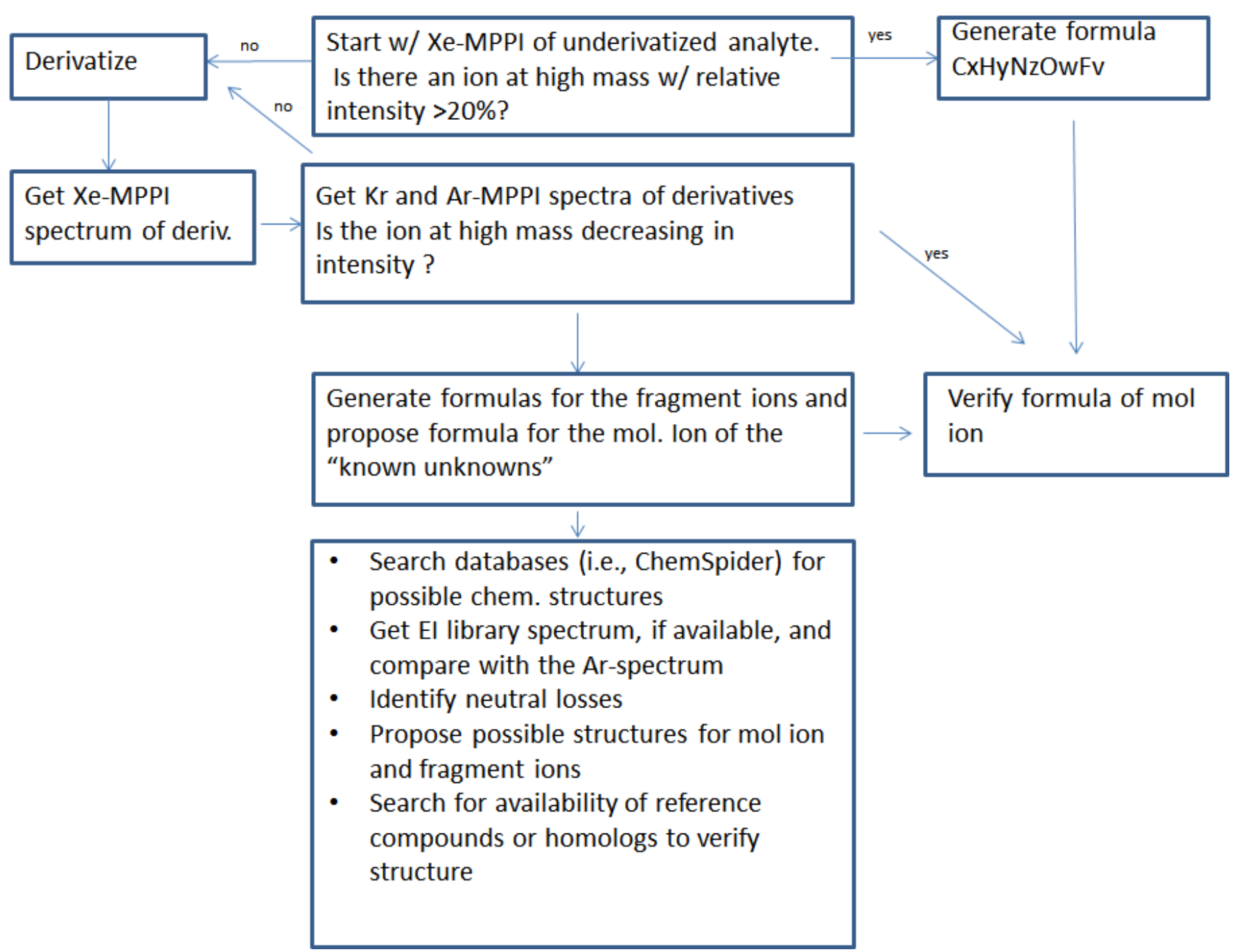

Figure 5: Proposed workflow

derivatization with TFAA and analysis using Xe-MPPI (Figure 2c) there was an abundant ion at $m / z 303.1077$ (relative intensity $100 \%$ ) from which the formula $\mathrm{C}_{14} \mathrm{H}_{16} \mathrm{NO}_{3} \mathrm{~F}_{3}$ was derived. The minimum requirement in generating this formula was at least three $\mathrm{F}$ atoms and one $\mathrm{O}$, because of the TFAA derivatization. When switching to the $\mathrm{Kr}$ - and then Ar-plasma, the relative intensity of the ion at $m / z 303.1077$ decreased (Figures $6 \mathrm{~b}$ and $6 \mathrm{c}$ ), which was an indication that this ion is the molecular ion, and fragment ions at $\mathrm{m} / \mathrm{z} 162.0675, \mathrm{~m} / \mathrm{z} 168.0631$, and $m / z 135.0529$ appeared. The molecular formulas assigned to these ions are $\mathrm{C}_{10} \mathrm{H}_{10} \mathrm{O}_{2}, \mathrm{C}_{6} \mathrm{H}_{9} \mathrm{~F}_{3} \mathrm{NO}$, and $\mathrm{C}_{8} \mathrm{H}_{7} \mathrm{O}_{2}$, respectively. It is interesting to note that the iminium ion, labeled with a TFA group, at $m / z 168.0631$ does not appear in the $\mathrm{Kr}$ spectrum. It is possible that the vertical ionization energy of this compound is $>10.6 \mathrm{eV}$ because of the electronegative effect of the three $\mathrm{F}$ atoms. Putting it all together, this "known unknown" has molecular formula $\mathrm{C}_{12} \mathrm{H}_{17} \mathrm{NO}_{2}$ (generated from $\mathrm{C}_{14} \mathrm{H}_{16} \mathrm{NO}_{3} \mathrm{~F}_{3}$ minus $\mathrm{COCF}_{3}$ plus $\mathrm{H}$ ), which is a homologue of MDMA, and has several common ions with MDMA. The fragment ions at $m / z 154.0493$ (Figure $4 \mathrm{~b}$ ) and $m / z 168.0631$ (Figure $6 \mathrm{c}$ ) provided the clue that that the amine functional group in this "known unknown" is substituted with an ethyl instead of a methyl group. This compound was identified as MDEA and is known to form an iminium ion $\mathrm{C}_{4} \mathrm{H}_{10} \mathrm{~N}$ in $\mathrm{EI}$ as well, but even when derivatized, the molecular ion of the TFA-deriva- tive is barely detectable in EI-MS [13]. The use of soft ionization, as demonstrated in this example, increased the relative abundance of the molecular ion, which is of utmost importance in the identification process of unknown substances. In addition, the use of accurate mass to generate the identities of the fragment ions helped to piece together the chemical structure of this compound. Without the molecular ion it would have been difficult to make such an identification even when using the Chemspider database with 26 million entries [17]. A search of this database for the molecular formula $\mathrm{C}_{12} \mathrm{H}_{17} \mathrm{NO}_{2}$ retrieved 4568 possible chemical formulae from which 15 had the 3,4-methylenedioxy-phenyl ring (Figure 7). Among these 15 possible structures, there were two tertiary amines with the ChemSpider IDs 367924 and 479880 that were eliminated from consideration as they cannot be derivatized with TFAA. From the remaining 13 possible chemical structures only one contains an ethyl group on the amine moiety, and that is the structure of MDEA. The fragmentation of this compound is shown in Figure 8.

Another "known unknown" which, when derivatized with TFAA, had the same accurate mass as the TFA derivative of MDEA, is discussed below. The Xe-MPPI spectrum of this compound shown in Figure 6d exhibited an abundant ion at $\mathrm{m} / z 207.1254$ (relative intensity $100 \%$ ) that is likely to be the 

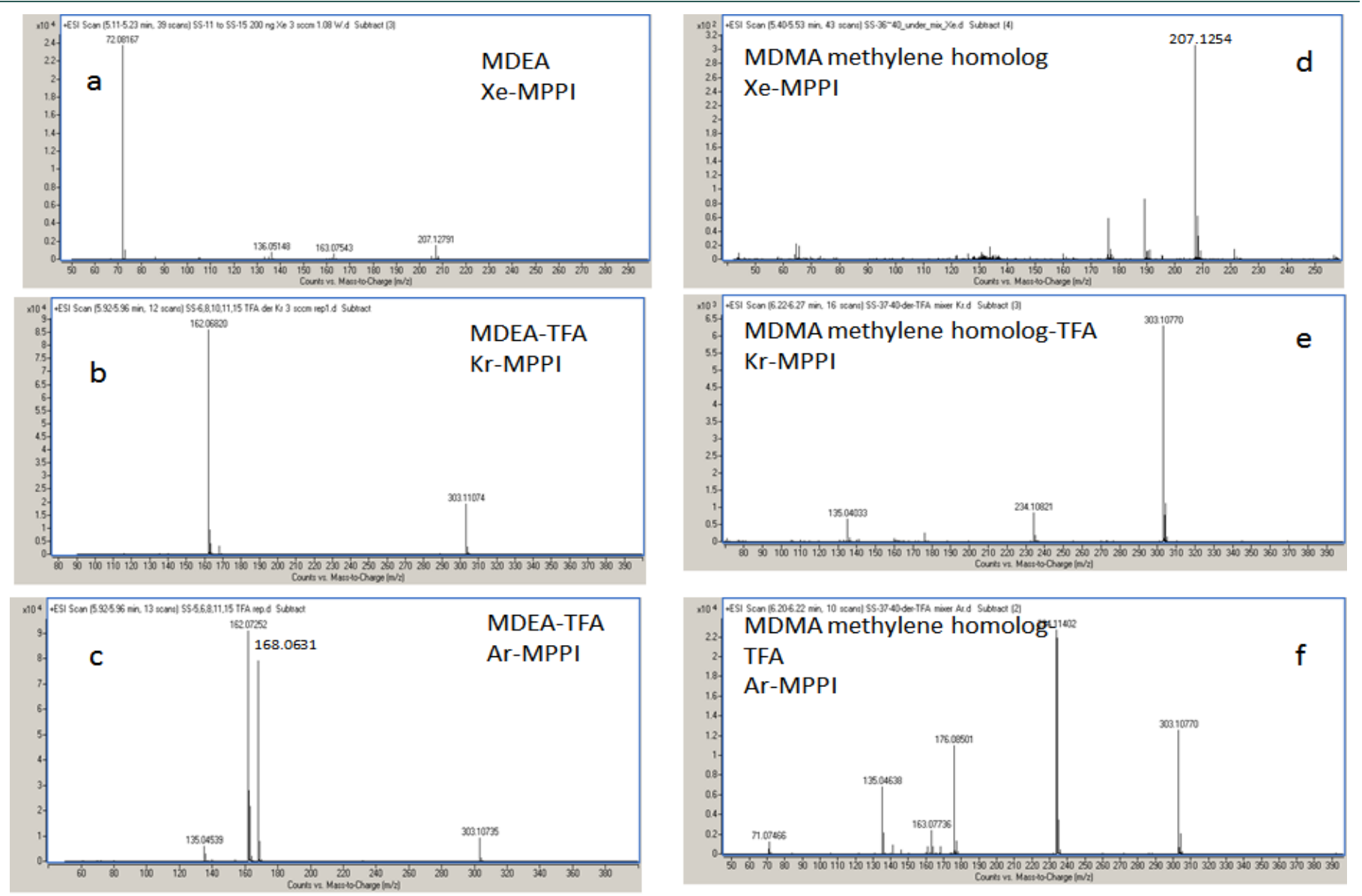

Figure 6: MPPI spectra of the underivatized (a,d) and TFA-derivatives of MDEA $(b, c)$ and MDMA methy-lene homolog (e,f). The spectra were obtained by GCTOFMS with the MPPI source using $\mathrm{Xe}, \mathrm{Kr}$ or $\mathrm{Ar}$<smiles>CCCCCNc1ccc2c(c1)OCO2</smiles>

24060326<smiles>CC(C)CNCc1ccc2c(c1)OCO2</smiles>

836222<smiles>CCC(C)NCc1ccc2c(c1)OCO2</smiles>

3904337<smiles>CCCNC(C)c1ccc2c(c1)OCO2</smiles>

24014617<smiles>CCN(CC)Cc1ccc2c(c1)OCO2</smiles>

367924<smiles>CC(C)CCNc1ccc2c(c1)OCO2</smiles>

24048752<smiles>CNC(C)(C)Cc1ccc2c(c1)OCO2</smiles>

21106335<smiles>CC(C)NCCc1ccc2c(c1)OCO2</smiles>

692396<smiles>CNC(C)CCc1ccc2c(c1)OCO2</smiles>

119255<smiles>CC(Cc1ccc2c(c1)OCO2)N(C)C</smiles>

479880<smiles>CC(C)NC(C)c1ccc2c(c1)OCO2</smiles>

24422984<smiles>CCCCNCc1ccc2c(c1)OCO2</smiles>

3909299<smiles>CC(C)(C)NCc1ccc2c(c1)OCO2</smiles>

836213<smiles>CCC(Cc1ccc2c(c1)OCO2)NC</smiles>

111153

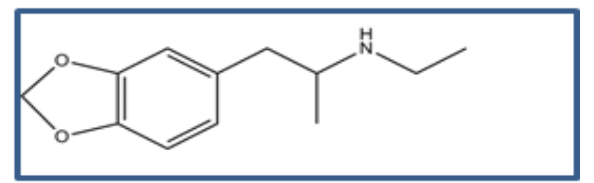

94775 - MDEA

Figure 7: Chemical structures for compounds retrieved from ChemSpider as possible candidates for $\mathrm{C}_{12} \mathrm{H}_{17} \mathrm{NO}_{2}$ 


\begin{tabular}{|c|c|c|c|c|c|c|c|c|c|c|}
\hline & $\left.\right|_{\mathrm{R}_{3}}$ & $\mathrm{COCF}_{3}$ & $\mathrm{R}_{2}^{\prime}$ & $\mathrm{R}_{3}$ & & & & $\mathrm{R}_{2}^{\prime}$ & $\downarrow$ & $\left.\right|_{\mathrm{R}_{3}}$ \\
\hline R3 & R4 & $\begin{array}{l}\text { Formula of fragment } \\
\text { ion A }\end{array}$ & Calc. $\mathrm{m} / \mathrm{z}$ & Compound name & $\mathrm{R}_{1}$ & $\mathrm{R}_{2}$ & $\mathrm{R}_{3}$ & $\mathrm{R}_{4}$ & $\begin{array}{l}\text { Formula of } \\
\text { fragment ion B }\end{array}$ & Calc. $\mathrm{m} / \mathrm{z}$ \\
\hline $\mathrm{CH}_{3}$ & $\mathrm{H}$ & $\mathrm{C}_{4} \mathrm{H}_{5} \mathrm{NOF}_{3}$ & 140.0318 & Amphetamine & $\mathrm{H}$ & H & $\mathrm{CH}_{3}$ & $\mathrm{H}$ & $\mathrm{C}_{9} \mathrm{H}_{10}$ & 118.0773 \\
\hline $\mathrm{CH}_{3}$ & $\mathrm{CH}_{3}$ & $\mathrm{C}_{5} \mathrm{H}_{7} \mathrm{NOF}_{3}$ & 154.0540 & Methamphetamine & $\mathrm{H}$ & $\mathrm{H}$ & $\mathrm{CH}_{3}$ & $\mathrm{CH}_{3}$ & $\mathrm{C}_{9} \mathrm{H}_{10}$ & 118.0773 \\
\hline$\frac{\mathrm{C}_{2} \mathrm{H}_{5}}{\mathrm{CH}_{3}}$ & $\frac{\mathrm{CH}_{3}}{\mathrm{C}_{2} \mathrm{H}_{5}}$ & $\frac{\mathrm{C}_{6} \mathrm{H}_{9} \mathrm{NOF}_{3}}{\mathrm{C}_{6} \mathrm{H}_{6} \mathrm{NOF}_{3}}$ & $\begin{array}{l}168.0631 \\
168.0631\end{array}$ & $\mathrm{~N}$-propylamphetamine & $\mathrm{H}$ & $\mathrm{H}$ & $\mathrm{CH}_{3}$ & $\mathrm{C}_{3} \mathrm{H}_{7}$ & $\mathrm{C}_{9} \mathrm{H}_{10}$ & 118.0773 \\
\hline $\mathrm{C}_{3} \mathrm{H}_{7}$ & $\mathrm{CH}_{3}$ & $\mathrm{C}_{7} \mathrm{H}_{11} \mathrm{NOF}_{3}$ & 182.0787 & Phentermine* & $\mathrm{H}$ & $\mathrm{H}$ & $\mathrm{CH}_{3}$ & $\mathrm{H}$ & $\mathrm{C}_{10} \mathrm{H}_{12}$ & 132.0934 \\
\hline $\mathrm{C}_{2} \mathrm{H}_{5}$ & $\mathrm{C}_{2} \mathrm{H}_{5}$ & $\mathrm{C}_{7} \mathrm{H}_{11} \mathrm{NOF}_{3}$ & 182.0787 & Fluoro-amphetamine & $\mathrm{F}$ & $\mathrm{H}$ & $\mathrm{H}$ & $\mathrm{H}$ & $\mathrm{C}_{9} \mathrm{H}_{9} \mathrm{~F}$ & 136.0683 \\
\hline & & & & Methyl-amphetamine & $\mathrm{CH}_{3}$ & $\mathrm{H}$ & $\mathrm{H}$ & $\mathrm{H}$ & $\mathrm{C}_{10} \mathrm{H}_{12}$ & 132.0934 \\
\hline & & & & Methoxy-amphetamine & $\mathrm{OCH}_{3}$ & $\mathrm{H}$ & $\mathrm{H}$ & $\mathrm{H}$ & $\mathrm{C}_{10} \mathrm{H}_{12} \mathrm{O}$ & 148.0883 \\
\hline & & & & MDA & $\mathrm{OCH}_{2} \mathrm{O}$ & & $\mathrm{H}$ & $\mathrm{H}$ & $\mathrm{C}_{10} \mathrm{H}_{10} \mathrm{O}_{2}$ & 162.0691 \\
\hline & & & & MDMA & $\mathrm{OCH}_{2} \mathrm{O}$ & & $\mathrm{H}$ & $\mathrm{CH}_{3}$ & $\mathrm{C}_{10} \mathrm{H}_{10} \mathrm{O}_{2}$ & 162.0691 \\
\hline & & & & MDEA & $\mathrm{OCH}_{2} \mathrm{O}$ & & $\mathrm{H}$ & $\mathrm{C}_{2} \mathrm{H}_{5}$ & $\mathrm{C}_{10} \mathrm{H}_{10} \mathrm{O}_{2}$ & 162.0691 \\
\hline
\end{tabular}

Figure 8: Fragmentation of the TFA-derivatized amphetamines using MPPI

molecular ion by being the ion at the highest $m / z$ in the Xe spectrum. The molecular formula of this ion, calculated with the MassHunter algorithm, is $\mathrm{C}_{12} \mathrm{H}_{17} \mathrm{NO}_{2}$. Upon derivatization with TFAA, there was an increase in mass from $\mathrm{m} / z 207.1254$ to $m / z 303.1077$, which corresponds exactly to the addition of $\mathrm{COCF}_{3}$ and the elimination of a $\mathrm{H}$ atom. The same requirements of a minimum of three $\mathrm{F}$ atoms and one $\mathrm{O}$ atom were applicable also to this TFA-derivative, so the ion at $\mathrm{m} / z 307.1077$ was attributed to the formula $\mathrm{C}_{14} \mathrm{H}_{16} \mathrm{NO}_{3} \mathrm{~F}_{3}$, as in the case of MDEA. The fragment ions in the Ar-MPPI spectrum (Figure 6f) were used to establish the chemical structure. The most abundant fragment ion at $m / z 234.1140$ corresponds to the loss of $\mathrm{CF}_{3}$ radical from the ion at $\mathrm{m} / z 303.1077$, and the ion at $\mathrm{m} / z$ 176.0850 corresponds to $\mathrm{C}_{11} \mathrm{H}_{12} \mathrm{O}_{2}$, which is a $14 \mathrm{u}$ shift from the fragment ion of MDEA at $\mathrm{m} / \mathrm{z}$ 162.0675. This would imply that the ion at $m / z 176.0850$ is a homolog of $\mathrm{C}_{10} \mathrm{H}_{10} \mathrm{O}_{2}$ and would have an extra methylene group. The chemical structure with the ChemSpider ID 111153 (Figure 7) is possible because a loss of the imine $\mathrm{NH}\left(\mathrm{CH}_{3}\right) \mathrm{COCF}_{3}$ would account for the ion at $m / z 176.0832$. However, there is a fragment ion in the Ar spectrum (not shown in 6f) at $m / z 44.0518$ with a relative intensity of $40 \%$ corresponding to $\mathrm{C}_{2} \mathrm{H}_{6} \mathrm{~N}$ (calc $\mathrm{m} / z$ 44.0495) that provided the clue that the methylene group must be between the tertiary carbon atom and the $\mathrm{N}$ atom. Furthermore, the ion at $m / z 135.0464$ in Figure $6 f$, with formula $\mathrm{C}_{8} \mathrm{H}_{7} \mathrm{O}_{2}$, was also present in the spectrum of the MDEA (Figure $6 \mathrm{c}$ ) and that ion is the 3,4-methylenedioxybenzyl ion. Finally, this formula was verified against the accurate mass measured with Xe plasma. This "known unknown" is the MDMA methylene homolog and has not made it into the ChemSpider database yet perhaps because of lacking a CAS number.

At the present time, the mass spectral library search is the primary tool in the identification process of unknown compounds analyzed with an EI source and the library search can also be performed when using soft ionization with either Ar, $\mathrm{Ne}(16 \mathrm{eV})$, or $\mathrm{He}(21.22 \mathrm{eV})$. The latter plasma gas has already been tested for many classes of compounds and the HeMPPI spectra are very similar to the EI spectra. However, the library search works only for compounds in the library and often retrieves similar spectra that make it difficult for the analyst to select the right candidate [18]. Better algorithms using fragmentation rule-based mass spectrum prediction are much needed, and they have to consider mass spectral characteristics under the guidance of classic fragmentation theories [18]. For a detailed review of strategies for structure elucidation based on discovery of spectral characteristics the reader is referred to Ref. 18 .

\section{Mass spectral fragmentation of amphetamines vs. cathinones}

Cathinones are an emerging group of designer drugs similar to amphetamines that contain derivatives of cathinone ( $\beta$-ketoamphetamine), $\beta$-ketoanalogs of 3,4-methylenedioxyamphetamines and pyrrolidinophenones. A detailed discussion of the mass spectral fragmentation of cathinones using 
soft ionization with the MPPI source has been published [15]. Some observations regarding their mass spectral fragmentation using the MPPI soft-ionization source are discussed below.

In general, derivatization is a must for both amphetamines and cathinones in order to distinguish them because, when using EI or even MPPI soft ionization, the mass spectrum of the underivatized compound is dominated by the iminium ion (Table 1) and the molecular ion is either too weak or not present. However, the TFA-derivatives of amphetamines yield a phenyl-propene radical cation or the 3,4-methylenedioxyphenyl-propene radical cation in the case of MDA, MDMA, and MDEA, whereas the TFA-derivatives of cathinones yield the benzoyl cation, so the two classes of designer drugs can be easily distinguished [15]. Furthermore, because the TFA derivatives of both amphetamines and cathinones yield the same iminium ions, it is recommended that the fragment ions corresponding to the McLafferty rearrangement ions (i.e., $\mathrm{C}_{10} \mathrm{H}_{12} \mathrm{O}$ at $m / z$ 148.0883), which are present only in the spectra of TFA-cathinones and not the TFA-amphetamines [15] be used for distinguishing between the TFA derivatives of cathinones and amphetamines.

\section{Derivatization with MTPA-pyrazole}

Derivatization with (+) a-methoxy-a-(trifluoromethyl)phenylacetyl-pyrazole (MTPA-pyrazole) reported by Matsushita et al.[11], was evaluated only to a limited extent in this study. The data indicate that the stereoisomers can be separated by GC and the chiral derivative provided similar information that could be used in structure elucidation. Specifically, the bulky $\alpha$-methoxy- $\alpha$-(trifluoromethyl)-phenylacetyl that replaces the hydrogen atom in the primary or the secondary amine group of the amphetamine-like designer drugs (i.e., MDA, MDMA, and MDEA) leads primarily to the formation of the 3,4-methylenedioxy-phenyl propene radical cation at $\mathrm{m} / z 162.0675$ via elimination of the imine-MTPA derivative (Figure 9). However, for amphetamine and methamphetamine that contain the phenyl ring and not the 3,4-methylenedioxyphenyl ring, the fragmentation with $\mathrm{Kr}$ plasma is dominated by the ions at $m / z 260.0976\left(\mathrm{C}_{12} \mathrm{H}_{13} \mathrm{~F}_{3} \mathrm{NO}_{2}\right)$ and $m / z 274.1102$ $\left(\mathrm{C}_{13} \mathrm{H}_{15} \mathrm{~F}_{3} \mathrm{NO}_{2}\right)$, corresponding to the loss of the benzyl radical from the molecular ion of the MTPA derivative of amphetamine and methamphetamine, respectively. It is interesting to note that the ion $\mathrm{C}_{10} \mathrm{H}_{12} \mathrm{NO}$ at $\mathrm{m} / z 162.0881$ in the mass spectrum of amphetamine-MTPA derivative is not the same as the ion $\mathrm{C}_{10} \mathrm{H}_{10} \mathrm{O}_{2}$ at $\mathrm{m} / \mathrm{z} 162.0682$ in the spectra of the MTPA derivatives of MDA, MDMA, and MDEA (Figure 9). This distinction can only be done by high-resolution MS (resolution $>7000)$.

What it is relevant about the derivatization with chiral MTPApyrazole is the fact that the MTPA-derivatives of the stereoisomers are separated chromatographically, which in the case of the TFA-derivatives they were not. Furthermore, the bulky MTPA group, which replaces the $\mathrm{H}$ atom in the primary and the secondary amine in the amphetamines that do not contain the 3,4-methylenedioxyphenyl ring, leads primarily to the formation of the MTPA-iminium ion via elimination of benzyl radical. The same iminium ions at $\mathrm{m} / \mathrm{z} 260.0945$ and $\mathrm{m} / \mathrm{z}$ 274.1003 were reported for a series of cathinones [15]. Regardless of the derivatization procedure used to replace the $\mathrm{H}$ atom in the primary or the secondary amine, the mass spectra of the derivatives obtained with the soft ionization source provide valuable information for structure elucidation.

\section{MPPI source sensitivity}

The MPPI source sensitivity reported here as signal-to-noise $(\mathrm{S} / \mathrm{N})$ ratio for three underivatized amphetamines spiked into a biological matrix was established at two concentrations corresponding to $0.5 \mathrm{ng}$ and $5 \mathrm{ng}$ per injection into the GC column. Figure 10 shows a total ion chromatogram (TIC) and extracted ion chromatograms (EICs) corresponding to the three amphetamines that were spiked into the biological matrix at $5 \mu \mathrm{g} / \mathrm{mL}$ (i.e., amphetamine, methamphetamine, and $\mathrm{N}, \mathrm{N}$-dimethylamphetamine) obtained with the Ar-plasma. In contrast to the detection sensitivity of hundred to several hundred ng at a $\mathrm{S} / \mathrm{N} \sim 3$, which was reported by Washida et al. [3] for GC-photoionization MS in 1978, the S/N reported here for the test amphetamines would represent almost a 4 orders of magnitude increase in sensitivity. The corresponding $\mathrm{S} / \mathrm{N}$ values measured at $0.5 \mathrm{ng}$ per injection for amphetamine, methamphetamine, N,N-dimethylamphetamine in the spiked biological matrix are 36,153 , and 480 , respectively. Other S/N measurements made with the MPPI source obtained by injecting 0.1-0.5 ng per injection ranged from 3 for codeine to 730 for caffeine [10]. What matters with this ionization source is that the noise level for Ar-MPPI ranges from 1.4-2.3 when using quantitation ions above $m / z 130$, but it is higher for $m / z$ $<70$ [10]. Nonetheless, when using the MPPI source the noise level is a lot lower than with an EI source. In the example shown here for the biological matrix the noise level for $\mathrm{m} / \mathrm{z}$ $<70$ was from 62 to 225 . Additional information regarding source linearity for model stimulants can be found in Ref. 10 .

\section{Conclusions}

The MPPI spectra of the TFA-derivatized amphetamines exhibit both the substituted-phenyl propene radical ions and iminium ions supporting their identification by MS. It has been demonstrated that by using Xe as plasma gas, the TFA derivatives of amphetamine-type designer drugs yield abundant molecular ions, and the relative intensities of the molecular ions, thus the degree of fragmentation, can be controlled with the plasma gas. Derivatization is needed because the MPPI spectra of the underivatized amphetamines are very similar to those generated by EI, thus leading to inconclusive MS identification even when using TOFMS. The derivatization with MTPApyrazole allowed the separation of the stereoisomers, but the bulky MTPA group that replaces the $\mathrm{H}$ atom in the primary and the secondary amine in the amphetamines leads primarily to the formation of the MTPA-iminium ion via elimination of benzyl radical. The TOFMS coupled with this "tunable" soft ionization source is a powerful analytical tool in the structure elucidation of designer drugs. 

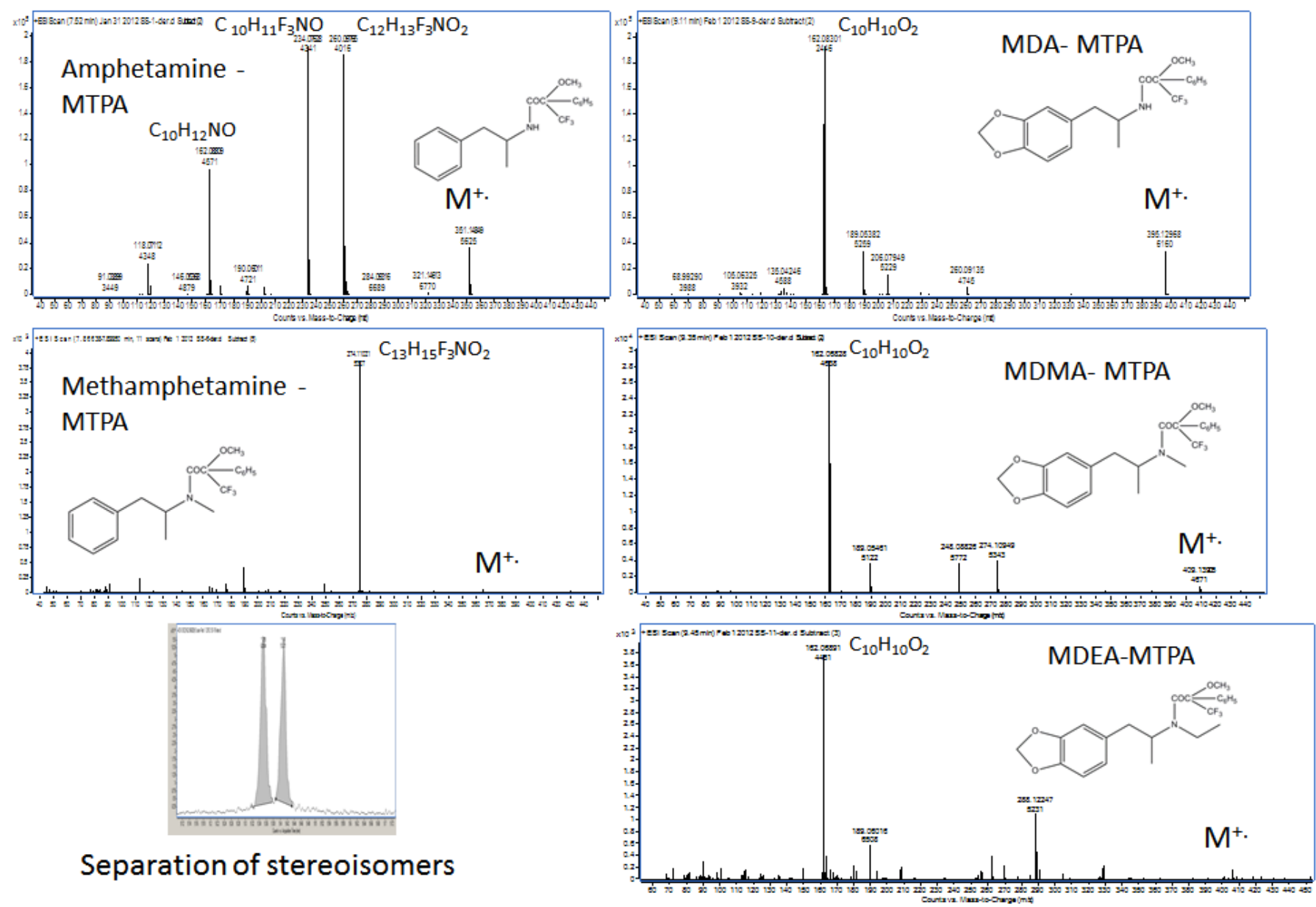

Separation of stereoisomers

TIC of spiked biological matrix

Figure 9: Kr-MPPI spectra of the MTPA derivatives obtained by GC-TOFMS with the MPPI source and Kr.

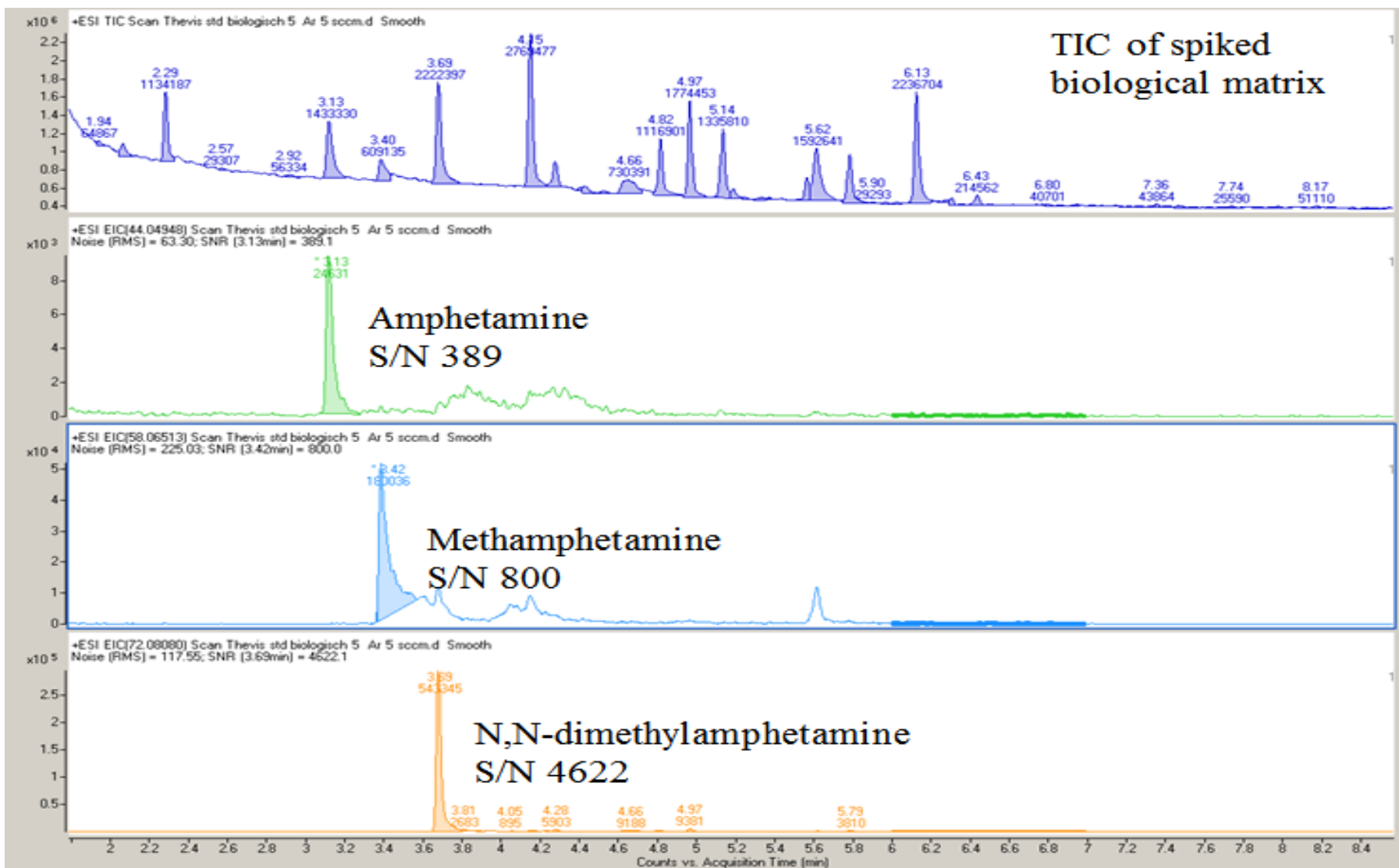

Figure 10: TIC and EICs for underivatized amphetamine $(\mathrm{m} / z$ 44.0495), methamphetamine $(\mathrm{m} / z$ 58.0651) and N,N-dimethylamphetamine $(m / z$ 72.0808) spiked into a biological matrix at $5 \mathrm{ng} / \mu \mathrm{L}$. The spiked biological matrix was from the WADA-accredited Laboratory at the German Sports Univ. Cologne, Germany. 


\section{Acknowledgements}

The author would like to acknowledge James Cooley (formerly with Agilent Technologies) and Randall Urdahl for the design of the MPPI source and George Yefchak and August Hidalgo for the MPPI source control software. The author thanks Professor Mario Thevis of the German Sports University in Cologne, Germany, for providing the biological extracts spiked with amphetamines and other stimulants and for reviewing the ms and Patrick Roach also for reviewing the ms prior to publication.

\section{References}

1. McLafferty FW (1980) Interpretation of Mass Spectra, Ch. 9, University Science Books, Mill Valley, CA.

2. Munson MSB, Field FH (1966) Chemical ionization mass spectrometry I. general introduction. J Am Chem Soc 88: 2621-30.

3. Washida N, Akimoto H, Takagi H, Okuda M (1978) Gas chromatography/ photoionization mass spectrometry. Anal Chem 50: 910-5.

4. Brettell TA, Butler JM, Almirall JR (2011) Forensic science. Anal Chem 83: 4539-56.

5. Thevis M (2010) Mass spectrometry in sports drug testing- Characterization of prohibited substances and doping control analytical assays, Ch.6, John Wiley \& Sons, Inc. Hoboken, NJ

6. Bogusz MJ, Krüger KD, Maier RD (2000) Analysis of underivatized amphetamines and related phenethylamines with high-performance liquid chromatography-atmospheric pressure chemical ionization mass spectrometry. J Anal Toxicol 24: 77-84.

7. Wu AH, Gerona R, Armenian P, French D, Petrie M, Lynch KL (2012) Role of liquid chromatography-high-resolution mass spectrometry (LC-HR/MS) in clinical toxicology. Clin Toxicol (Phila) 50: 733-42.
8. Nakazono Y, Tsujikawa K, Kuwayama K, Kanamori F, Iwata YT, et al. (2013) Differentiation of regioisomeric fluoroamphetamine analogs by gas chromatography-mass spectrometry and liquid chromatography-tandem mass spectrometry. Forensic Toxicol 31: 241-50.

9. Sekuła K, Zuba D (2013) Structural elucidation and identification of a new derivative of phenethylamine using quadrupole time-of-flight mass spectrometry. Rapid Commun Mass Spectrom 27: 2081-90.

10. Lopez-Avila V, Cooley J, Urdahl R, Thevis M (2012) Determination of stimulants using gas chromatography/high-resolution time-of-flight mass spectrometry and a soft ionization source. Rapid Commun Mass Spectrom 26: 2714-24.

11. Matsushita T, Takatsu M, Yoshida Y, Moriyasu M (2007) Development of new on-column chiral derivatization reagent for gas chromatographic separation of optical isomeric amphetamine and methamphetamine. Bunseki Kagaku 56:1089-95.

12. Rösner P, Quednow B, Girreser U, Junge T (2005) Isomeric fluoro-methoxy-phenylalkylamines: a new series of controlled-substance analogues (designer drugs). Forensic Sci Int 148:143-56.

13. Kumazawa T, Hara K, Hasegawa C, Uchigasaki S, Lee X-P, et al. (2011) Fragmentation pathways of trifluoroacetyl derivatives of methamphetamine, amphetamine, and methylenedioxyphenylalkylamine designer drugs by gas chromatography/mass spectrometry. Intern J Spectroscopy 2011: 318148.

14. Belal T, Awad T, Clark CR, DeRuiter J (2009) GC-MS evaluation of a series of acylated derivatives of 3,4-methylenedioxymethamphetamine. J Chromatogr Sci 47: 359-64.

15. Lopez-Avila V, Gao W, Urdahl R (2012) Mass spectral fragmentation of cathinones by high-resolution TOFMS using a soft ionization source. J Pharmaceutical Scientific Innovation 1:44-53.

16. Lopez-Avila V, Roach PJ, Urdahl R (2013) Environmental applications of soft ionization with GC-TOFMS and GC-QTOFMS. Ch. 14 Elsevier book edited by Imma Ferrer and Michael Thurman ( 2013 in print).

17. Little JL, Williams AJ, Pshenichnov A, Tkachenko V (2012) Identification of "known unknowns" utilizing accurate mass data and ChemSpider. J Am Soc Mass Spectrom 23: 179-85.

18. Zhang L, Tang C, Cao D, Zeng Y, Tan B, et al. (2013) Strategies for structure elucidation of small molecules using gas chromatography-mass spectrometric data. Trends Anal Chem 47: 37- 46.

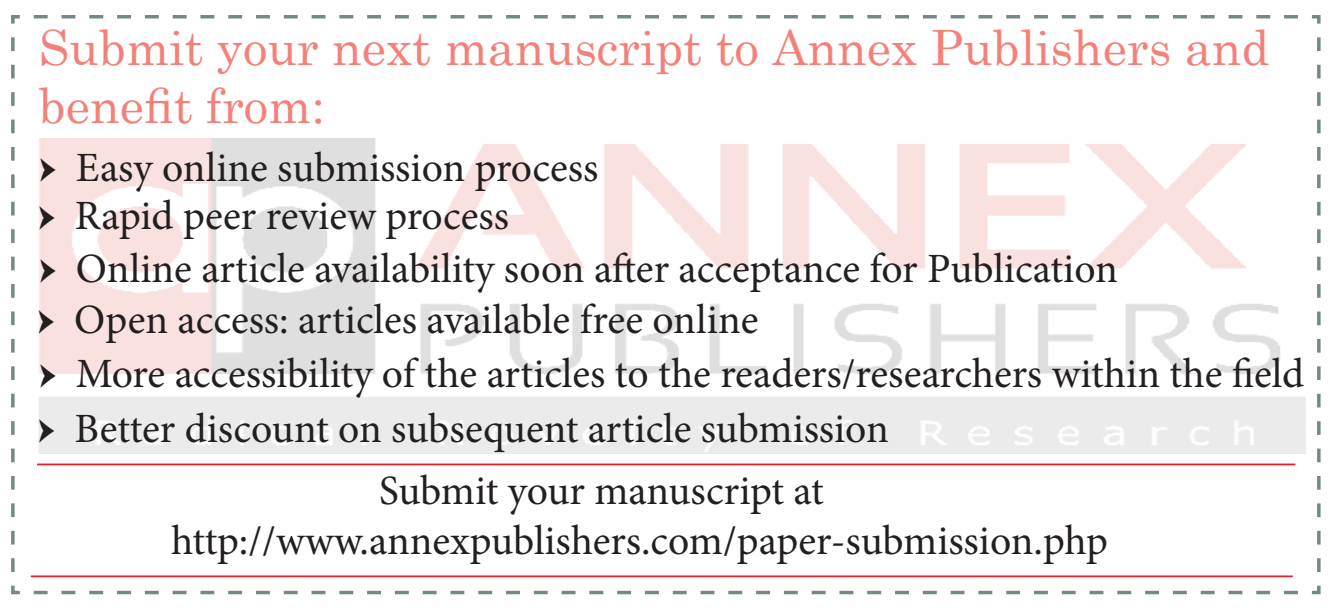

